\title{
Comparison of the monoamine transporters from human and mouse in their sensitivities to psychostimulant drugs Dawn D Han ${ }^{1}$ and Howard H Gu*1,2
}

Address: ${ }^{1}$ Department of Pharmacology, The Ohio State University College of Medicine, USA and ${ }^{2}$ Department of Psychiatry, The Ohio State University College of Medicine, 333 West 10th Avenue, Columbus, Ohio 43210, USA

Email: Dawn D Han - han.195@osu.edu; Howard H Gu* - gu.37@osu.edu

* Corresponding author

Published: 03 March 2006

BMC Pharmacology2006, 6:6 doi:10.1 |86/|47|-22/0-6-6

This article is available from: http://www.biomedcentral.com/I47I-22/0/6/6

(C) 2006Han and Gu; licensee BioMed Central Ltd.

This is an Open Access article distributed under the terms of the Creative Commons Attribution License (http://creativecommons.org/licenses/by/2.0), which permits unrestricted use, distribution, and reproduction in any medium, provided the original work is properly cited.
Received: 03 November 2005

Accepted: 03 March 2006

\begin{abstract}
Background: The plasma membrane neurotransmitter transporters terminate neurotransmissions by the reuptake of the released neurotransmitters. The transporters for the monoamines dopamine, norepinephrine, and serotonin (DAT, NET, and SERT) are targets for several popular psychostimulant drugs of abuse. The potencies of the psychostimulant on the monoamine transporters have been studied by several laboratories. However, there are significant discrepancies in the reported data with differences up to 60 -fold. In addition, the drug potencies of the 3 monoamine transporters from mouse have not been compared in the same experiments or along side the human transporters. Further studies and systematic comparisons are needed.

Results: In this study, we compared the potencies of five psychostimulant drugs to inhibit human and mouse DAT, SERT and NET in the same cellular background. The $K_{1}$ values of cocaine to inhibit the 3 transporters are within a narrow range of 0.2 to $0.7 \mu \mathrm{M}$. In comparison, methylphenidate inhibited DAT and NET at around $0.1 \mu \mathrm{M}$, while it inhibited SERT at around $100 \mu \mathrm{M}$. The order of amphetamine potencies was NET $\left(K_{1}=0.07-0.1 \mu M\right)$, DAT $\left(K_{1} \approx 0.6 \mu \mathrm{M}\right)$, and SERT $\left(K_{1}\right.$ between 20 to $40 \mu \mathrm{M})$. The results for methamphetamine were similar to those for amphetamine. In contrast, another amphetamine derivative, MDMA (3-4 methylenedioxymethamphetamine), exhibited higher potency at SERT than at DAT. The human and mouse transporters were similar in their sensitivities to each of the tested drugs ( $K_{1}$ values are within 4 -fold).

Conclusion: The current and previous studies support the following conclusions: I) cocaine blocks all 3 monoamine transporters at similar concentrations; 2) methylphenidate inhibits DAT and NET well but a 1000-fold higher concentration of the drug is required to inhibit SERT; 3) Amphetamine and methamphetamine are most potent at NET, while being 5 - to 9-fold less potent at DAT, and 200- to 500-fold less potent at SERT; 4) MDMA has moderately higher apparent affinity for SERT and NET than for DAT. The relative potencies of a drug to inhibit DAT, NET and SERT suggest which neurotransmitter systems are disrupted the most by each of these stimulants and thus the likely primary mechanism of drug action.
\end{abstract}




\section{Background}

Drug abuse is a serious problem in the United States and around the world that places tremendous social and economical burdens on individuals and on the whole society [1]. Psychostimulants are a group of drugs that stimulate the activity of the central nervous system and produce a series of effects in humans, such as increasing heart rate and respiration, improving alertness, elevating mood and self-confidence, and producing euphoria [2]. Common psychostimulant drugs include: cocaine, methylphenidate (Ritalin), amphetamine, methamphetamine, and MDMA [2]. Some of these psychostimulants are useful medications that have long been used for treating various disorders such as attention deficit hyperactivity disorder (ADHD), narcolepsy, and obesity, while they are also addictive substances that could cause serious adverse effects when abused [2]. Psychostimulant abuse is a major public health problem in the United States. According to the 2003 National Survey on Drug Use and Health [3], cocaine and amphetamine are two of the most abused drugs while methamphetamine abuse has become a growing concern and 12.3 million Americans age twelve and older had tried methamphetamine at least once in their lifetimes. Methylphenidate is commonly prescribed as Ritalin to treat ADHD. As the number of Ritalin prescription increases, drug and law enforcement agencies are seeing an increase in Ritalin drug dealing and the illicit use of Ritalin as a recreational drug [3]. The abuse of MDMA, also known as Ecstasy, has also spread to a wide range of settings and demographic subgroups and more than 10 million people have tried MDMA at least once [3].

Plasma membrane neurotransmitter transporters terminate neurotransmissions by the reuptake and recycling of the released neurotransmitters [4,5]. The transporters for the monoamines dopamine, norepinephrine, and serotonin (DAT, NET, and SERT) belong to a family of $\mathrm{Na}^{+} / \mathrm{Cl}^{-}$ -dependent neurotransmitter transporters, which are intrinsic membrane proteins containing 12 putative transmembrane domains [6,7]. Psychostimulants, such as cocaine, methylphenidate, and amphetamine related compounds interrupt the reuptake process by DAT, NET and SERT [8-11]. Consequently, neurotransmissions are prolonged and the extracellular concentrations of these amine transmitters are elevated, resulting in complex neurochemical changes and profound psychiatric effects [12]. In order to understand the effects of these psychostimulant drugs, it is critical to determine which transporter or neurotransmitter systems are most affected at low, medium, or high drug doses. A thorough understanding of the pharmacological profile for each psychostimulant drug would be helpful for the development of treatment protocols for stimulant overdose and dependence.
The potencies of different psychostimulant drugs at the monoamine transporters have been studied and reported by different laboratories [9,10,13-15]. However, there are significant discrepancies among the reported data and the differences are up to 60-fold. For instance, the inhibition constant $\left(\mathrm{K}_{\mathrm{I}}\right)$ for amphetamine to inhibit DA uptake in rat synaptosomes was reported to be $0.034 \mu \mathrm{M}$ in one study [16], while it was reported to be $2.3 \mu \mathrm{M}$ in cultured cells expressing rat DAT [9]. The MDMA $\mathrm{K}_{\mathrm{I}}$ value to inhibit rat SERT was determined to be $0.24 \mu \mathrm{M}$ [15] and 2.6 $\mu \mathrm{M}$ [13]. The $\mathrm{K}_{\mathrm{I}}$ values for cocaine to inhibit rat DAT in vitro ranged from $0.33 \mu \mathrm{M}$ to $2.0 \mu \mathrm{M}[9,17]$. These differences are likely due to different experimental procedures employed by each laboratory, the different expression systems or tissue preparation methods used, and different qualities of drugs used.

Therefore, it is important to compare DAT, NET and SERT in their responses to psychostimulants in the same cellular background, using a uniform protocol and drugs. One of our earlier studies compared the cloned DAT, NET and SERT transporters stably expressed in LLC-PK1 cells, but the available transporter cDNAs were from different species [10]. In another study, human clones of the DAT, NET and SERT transporters were stably expressed in HEK293 cells and the uptake inhibition by selected drugs including some psychostimulants were compared [14]. Several other studies examined rat transporters using synaptosomes prepared from rat brains $[13,15,18,19]$. So far, there is no study focusing on the comparison of psychostimulant potencies among the mouse monoamine transporters and how they compare to the human transporters. With the ever wider use of genetically modified mouse models in recent years, experimental data that compare drug effects between human and mouse monoamine transporters are becoming increasingly important.

In the present study, we compared the potencies of five psychostimulant drugs in inhibiting human and mouse monoamine transporters in the same background and using the same procedure. The drugs examined were cocaine, methylphenidate, amphetamine, methamphetamine, and MDMA. Our results provide new information and confirm most of the published data while differ from some of the previous results. This study, combined with results from other studies, provides very useful information about which neurotransmission pathways are likely to be affected the most by each of the drugs, which gives insight into primary mechanisms of drug actions.

\section{Results and discussion}

Transiently transfected cells are used to determine the $\mathrm{K}_{\mathrm{I}}$ values for drugs inhibiting wild type and mutant monoamine transporters in our laboratory and other laboratories [20-26]. Fluctuations in transporter expression 

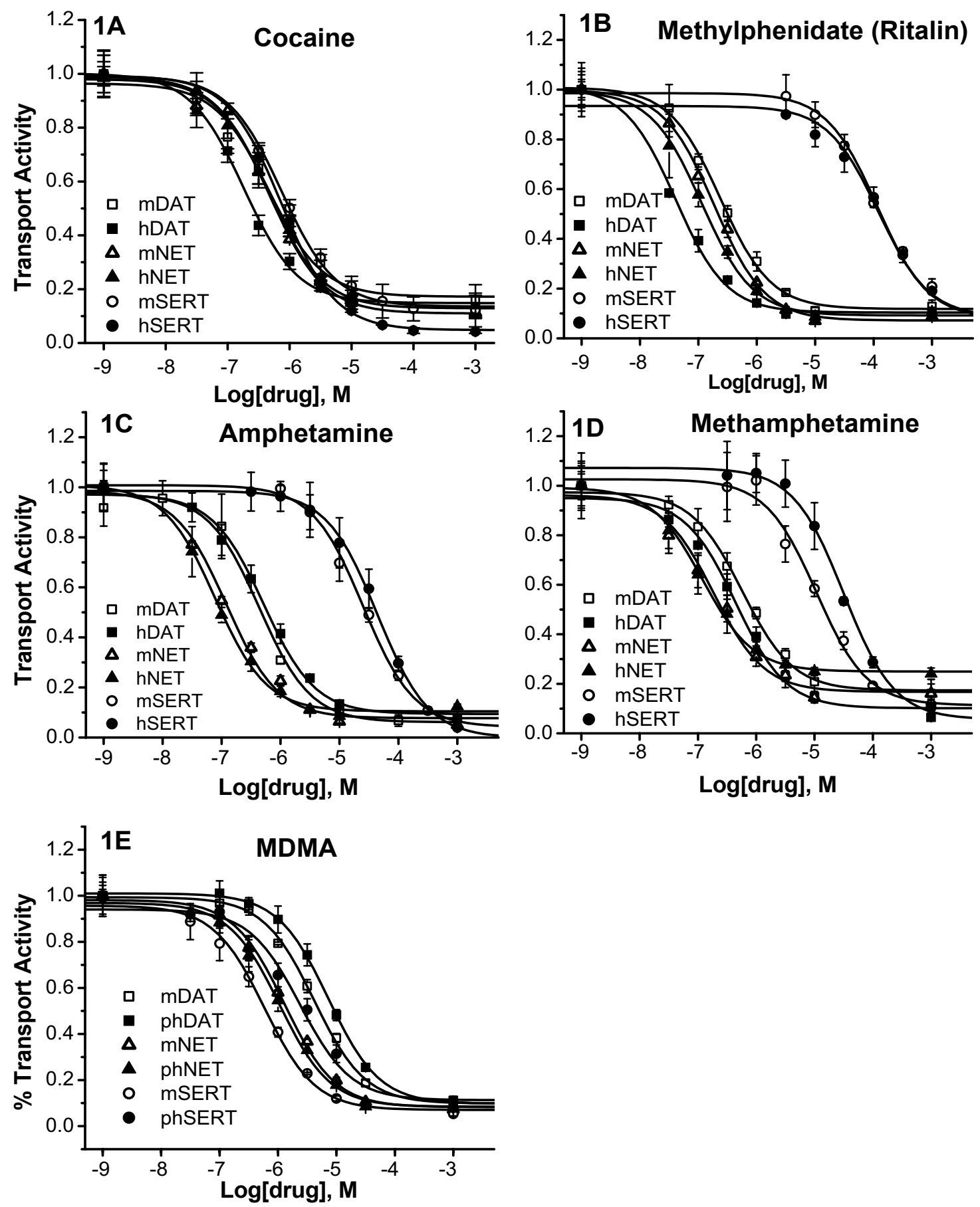

Figure I

Drug inhibition profiles of mouse and human monoamine transporters by psychostimulants. Intestine 407 cells were transfected with human or mouse DAT, SERT, or NET cDNAs. Twenty to 24 hours after transfection, cells were incubated with $\left[{ }^{3} \mathrm{H}\right]$ labeled substrate in $\mathrm{PBS} / \mathrm{Mg} / \mathrm{Ca}$ buffer for $10 \mathrm{~min}$ in the absence or presence of increasing concentrations of a psychostimulant drug as indicated. Uptake was terminated by two successive washes with $\mathrm{PBS} / \mathrm{Mg} / \mathrm{Ca}$. The amounts of [ $\left.{ }^{3} \mathrm{H}\right]$ labeled substrate accumulated in the cells were determined by scintillation counting. The uptake activities are presented as fractional activities relative to those in the absence of drugs. The experiments were performed in triplicates. Each data point is expressed as mean \pm SEM. The five drugs tested are: A) Cocaine; B) Methylphenidate (Ritalin); C) Amphetamine; D) Methamphetamine; and E) MDMA. 
Table I: Comparison of the $K_{1}$ values of 5 psychostimulants to inhibit human and mouse monoamine transporters.

\begin{tabular}{|c|c|c|c|c|c|}
\hline Drug & Cocaine & Methylphenidate & Amphetamine & Methamphetamine & MDMA \\
\hline \multicolumn{6}{|c|}{ Human } \\
\hline hDAT & $0.23 \pm 0.03$ & $0.06 \pm 0.01$ & $0.64 \pm 0.14$ & $0.46 \pm 0.06$ & $8.29 \pm 1.67$ \\
\hline hNET & $0.48 \pm 0.05$ & $0.10 \pm 0.01$ & $0.07 \pm 0.01$ & $0.11 \pm 0.01$ & $1.19 \pm 0.13$ \\
\hline hSERT & $0.74 \pm 0.03$ & $|32.43 \pm 10.7|$ & $38.46 \pm 3.84$ & $31.74 \pm 2.40$ & $2.41 \pm 0.73$ \\
\hline Ratio I & 3.2 & 2207 & 549 & 288 & 7.0 \\
\hline \multicolumn{6}{|c|}{ Mouse } \\
\hline mDAT & $0.49 \pm 0.042$ & $0.26 \pm 0.03$ & $0.56 \pm 0.11$ & $0.47 \pm 0.08$ & $4.87 \pm 0.65$ \\
\hline mNET & $0.46 \pm 0.062$ & $0.17 \pm 0.03$ & $0.12 \pm 0.02$ & $0.19 \pm 0.05$ & $1.75 \pm 0.5 \mathrm{I}$ \\
\hline MSERT & $0.73 \pm 0.12$ & $\mid 14.37 \pm 7.61$ & $23.82 \pm 1.71$ & $9.28 \pm 0.86$ & $0.64 \pm 0.05$ \\
\hline Ratio I & 1.6 & 672 & 199 & 49 & 7.6 \\
\hline
\end{tabular}

The $K_{1}$ values (in $\mu \mathrm{M}$ ) were determined as illustrated in Fig. I. They are expressed as mean \pm S.E.M. of four to seven experiments. 1 The ratios of highest $K_{1}$ values over the lowest are shown to highlight the differences. ${ }^{2}$ The difference between these two $K_{1}$ values was not statistically significant (ANOVA post hoc Bonferroni test, $\mathrm{p}>0.05$ ); all other values were statistically different (ANOVA comparing the three transporters within the same species and for the same drug).

levels have little impact on $\mathrm{K}_{\mathrm{I}}$ measurement except when expression levels are very low resulting in unacceptable signal to noise ratio. In this study, human and mouse DAT, NET, and SERT cDNAs were transiently expressed in cultured Intestine 407 cells. Transport activities by the transfected cells were measured in the presence of increasing concentrations of drugs. The KI values were then determined. Five psychostimulant drugs were studied: cocaine, methylphenidate, amphetamine, methamphetamine, and MDMA. For each of these drugs, the transporters were studied in the same experiments for more precise comparison. Fig. 1 shows representative results for each of the 5 drugs. The results are summarized in Table 1 displaying the average $\mathrm{K}_{\mathrm{I}}$ values from 4-7 experiments. The ratios of highest $\mathrm{K}_{\mathrm{I}}$ values over the lowest were calculated to highlight the differences. The results and conclusions from this study were obtained using Intestine 407 cells, which may not apply to other cell lines or in vivo systems.

\section{Cocaine}

Fig. 1A shows that cocaine inhibited DAT, SERT, and NET from human or mouse within a narrow range of concentrations. The $\mathrm{K}_{\mathrm{I}}$ values were from 0.2 to $0.7 \mu \mathrm{M}$. Among the human monoamine transporters, cocaine was a slightly more potent inhibitor of hDAT $\left(\mathrm{K}_{\mathrm{I}}=0.23 \mu \mathrm{m}\right)$ than hSERT $\left(\mathrm{K}_{\mathrm{I}}=0.74 \mu \mathrm{m}\right)$ with $\mathrm{hNET}$ in the middle $\left(\mathrm{K}_{\mathrm{I}}=\right.$ $0.48 \mu \mathrm{m})$. The cocaine potencies that inhibit mouse transporters were very similar to those for the human transporters except that the $\mathrm{K}_{\mathrm{I}}$ for mDAT $(0.49 \mu \mathrm{m})$ was about twice the value for hDAT. Compared to earlier studies, our $\mathrm{K}_{\mathrm{I}}$ value $(0.23 \mu \mathrm{M})$ for hDAT was similar to the $\mathrm{K}_{\mathrm{I}}$ value $(0.278 \mu \mathrm{M})$ reported by Eshleman, et al. for hDAT stably expressed in HEK293 cells [14] but 4 times the value $\left(\mathrm{K}_{\mathrm{I}}=\right.$ $0.058 \mu \mathrm{M}$ ) reported by Giros, et al. for hDAT expressed in mouse fibroblast Ltk-cells [27]. For both human and mouse NET and SERT, our data indicated that NET is slightly more sensitive to cocaine than SERT, while two previous studies using rat synaptosomes or human trans- porters expressed in cultured cells [14,15] suggest that SERT is slightly more sensitive to cocaine than NET. Despite the small differences, all studies show that cocaine inhibits DAT, NET and SERT within a narrow concentration range, suggesting that modulation of all three neurotransmitter systems are likely to contribute to the biochemical and behavioural effects of cocaine.

\section{Methylphenidate (Ritalin)}

As shown in Fig. 1B and Table 1, methylphenidate was a very potent inhibitor of hDAT and hNET $\left(\mathrm{K}_{\mathrm{I}}=0.06 \mu \mathrm{M}\right.$ and $0.10 \mu \mathrm{M})$, while it was not a potent inhibitor of hSERT $\left(K_{I}=132 \mu \mathrm{M}\right)$. Therefore, hSERT is over 2000 fold less sensitive to methylphenidate than hDAT. Comparison between the two species revealed that methylphenidate was 4 -fold more potent to inhibit hDAT than mDAT, while it had similar effects on NET or SERT from the two species. Our data show trends similar to those previously reported for human transporters expressed in HEK cells [14] and for rat transporters studied with rat brain synaptosomes [13]. For instance, the methylphenidate $\mathrm{K}_{\mathrm{I}}$ values determined by Eshleman et al are $0.19 \mu \mathrm{M}$ for hDAT, $0.038 \mu \mathrm{M}$ for hNET and $55 \mu \mathrm{M}$ for hSERT [14]. The common conclusion from all these studies is that SERT is much less sensitive to methylphenidate than DAT and NET.

Methylphenidate is marketed as Ritalin and is prescribed to treat ADHD particularly for children. This prescription drug is also addictive and has been abused. It has been reported that cocaine and methylphenidate accumulate in the same regions in the human brain and have similar effectiveness in blocking DAT in vitro and in vivo [28]. However, methylphenidate abuse by humans is much less frequent than that for cocaine [29]. The major difference between methylphenidate and cocaine is that SERT is not significantly inhibited by methylphenidate with doses that completely block DAT and NET while cocaine blocks 
all three transporters equally well. This difference likely contributes to the different effects produced by the two drugs. Another likely contributing factor is the different pharmacokinetics for the two drugs with cocaine reaching its site of action much more rapidly than methylphenidate.

\section{Amphetamine and methamphetamine}

Among human transporters, amphetamine was most potent at inhibiting hNET $\left(\mathrm{K}_{\mathrm{I}}=0.07 \mu \mathrm{M}\right)$. Compared to the amount of amphetamine required to inhibit hNET, 9fold and over 500-fold more amphetamine was required to inhibit hDAT $\left(\mathrm{K}_{\mathrm{I}}=0.64 \mu \mathrm{M}\right)$ and hSERT $\left(\mathrm{K}_{\mathrm{I}}=38 \mu \mathrm{M}\right)$ respectively. The potencies of methamphetamine (Fig. $1 \mathrm{D})$ to inhibit human and mouse monoamine transporters are similar to those of amphetamine (Fig. 1C). We compared the human and mouse monoamine transporters and found that the transporters from the two spices responded to amphetamine and methamphetamine in a similar fashion (Fig. 1C, 1D, and Table 1). Our results are not the same as those from previous studies but show a similar trend. In one study with rat synaptosomes, the amphetamine $\mathrm{K}_{\mathrm{I}}$ values are $0.034 \mu \mathrm{M}$ for rDAT, $0.039 \mu \mathrm{M}$ for rNET, and $3.8 \mu \mathrm{M}$ for rSERT [15]. In another study using cultured cells expressing human transporters, the methamphetamine $\mathrm{K}_{\mathrm{I}}$ values are $0.082 \mu \mathrm{M}$ for hDAT, $0.0013 \mu \mathrm{M}$ for rNET, and $20.7 \mu \mathrm{M}$ for hSERT. Therefore, amphetamine and methamphetamine are at least 100fold less potent at inhibiting SERT than DAT or NET.

Amphetamine is a synthetic drug. While prescribed for treating ADHD, amphetamine has also been frequently diverted from prescription to recreational use. Methamphetamine is an amphetamine analogue which also has some limited therapeutic uses, primarily in the treatment of ADHD and obesity. In recent years, the abuse of methamphetamine becomes an extremely serious and growing problem. Amphetamine and its analogues are also substrates of the monoamine transporters and the vesicular monoamine transporter. They compete with and exchange with monoamines at the plasma membrane transporters and also at the vesicular monoamine transporter, disrupting the reuptake process and causing the release of monoamines [7,30]. Amphetamine induced monoamine release is usually studied using animal brain preparations which contain both the plasma membrane and vesicular monoamine transporters. Cultured cells expressing only plasma membrane transporters are usually used to measure the $\mathrm{K}_{\mathrm{I}}$ values of uptake inhibition which reflect the apparent affinities of the drugs to each transporter. The $\mathrm{K}_{\mathrm{I}}$ value includes the effect of amphetamine induced substrate release and it is not exactly the same as the dissociation constant $\mathrm{K}_{\mathrm{D}^{\prime}}$ a true measurement of drug affinity. In this study, we focused on comparing $\mathrm{K}_{\mathrm{I}}$ values of the transporters and did not study drug induced releases. The results show that amphetamine and methamphetamine are most potent in inhibiting NET and much less potent in inhibiting SERT in both human and mouse.

\section{MDMA}

As its name indicated, 3,4-methylenedioxymethamphetamine is a compound with a methylenedioxy group added to methamphetamine. The chemical modification substantially increases MDMA's potency to inhibit SERT while reducing its potencies to inhibit DAT and NET compared to methamphetamine. This brings the $\mathrm{K}_{\mathrm{I}}$ values for all three monoamine transporters to a close range (7fold). In mouse, the order of potencies for MDMA was SERT $\left(K_{I}=0.64 \mu \mathrm{M}\right)$, NET $\left(K_{I}=1.75 \mu \mathrm{M}\right)$, and DAT $\left(K_{I}=\right.$ $4.87 \mu \mathrm{M})$. For human transporters, the order was NET $\left(\mathrm{K}_{\mathrm{I}}\right.$ $=1.19 \mu \mathrm{M})$, SERT $\left(\mathrm{K}_{\mathrm{I}}=2.41 \mu \mathrm{M}\right)$, and DAT $\left(\mathrm{K}_{\mathrm{I}}=8.29 \mu \mathrm{M}\right)$. In previous studies, Rothman, et al. has reported that among the rat transporters, MDMA is most potent at inhibiting rSERT $\left(\mathrm{K}_{\mathrm{I}}=0.238 \mu \mathrm{M}\right)$, followed by $\operatorname{rNET}\left(\mathrm{K}_{\mathrm{I}}=\right.$ $0.462 \mu \mathrm{M})$ and $\operatorname{rDAT}\left(\mathrm{K}_{\mathrm{I}}=1.572 \mu \mathrm{M}\right)$ [15]. However, another study has reported that MDMA is more potent at inhibiting $\operatorname{rDAT}\left(\mathrm{K}_{\mathrm{I}}=1.53 \mu \mathrm{M}\right)$ than $\operatorname{rSERT}\left(\mathrm{K}_{\mathrm{I}}=2.6 \mu \mathrm{M}\right)$ [13]. Our data for the mouse and human transporters are similar to the results by Rothman et al for rat transporters [15]. Our results indicate that MDMA is more potent in inhibiting SERT than DAT, which is in contrary to the other amphetamine derivatives.

\section{Conclusion}

There are significant discrepancies in previous studies on the potencies of psychostimulant drugs at monoamine transporters, likely due to differences in experimental setups, expression systems, tissue preparations, and/or drug qualities. In this study, we compared the potencies of five commonly abused psychostimulants at the human and mouse DAT, SERT and NET in the same cellular background. Cocaine blocked the 3 monoamine transporters at similar concentrations $\left(K_{I}=0.2-0.7 \mu \mathrm{M}\right)$. In comparison, methylphenidate inhibited DAT and NET around 0.1 $\mu \mathrm{M}$, while inhibited SERT at 1000 fold higher concentration (around $100 \mu \mathrm{M}$ ). Amphetamine and methamphetamine were most potent for NET $\left(\mathrm{K}_{\mathrm{I}}\right.$ around $\left.0.1 \mu \mathrm{M}\right)$, less potent for DAT $\left(\mathrm{K}_{\mathrm{I}}\right.$ around $\left.0.5 \mu \mathrm{M}\right)$, and much less potent for SERT ( $\mathrm{K}_{\mathrm{I}}$ between 10 to $40 \mu \mathrm{M}$ ). In contrast, MDMA, another amphetamine derivative, exhibited higher potency at SERT than at DAT. The human and mouse transporters were similar in their sensitivities to each of the tested drugs ( $\mathrm{K}_{\mathrm{I}}$ values within 4 folds). The relative potencies of a drug in inhibiting DAT, NET and SERT suggest the neurotransmitter systems that are disrupted the most and thus the primary mechanism of drug action. 


\section{Methods \\ Materials}

Cocaine, D-amphetamine, and methylphenidate were kindly provided by National Institute on Drug Abuse through its Drug Supply Program. D-methamphetamine and MDMA were purchased from Sigma (St Louis, MO). $\left[{ }^{3} \mathrm{H}\right]$-labelled dopamine $(23.5 \mathrm{Ci} / \mathrm{mmole})$ and $\left[{ }^{3} \mathrm{H}\right]-$ labelled serotonin $(27.1 \mathrm{Ci} / \mathrm{mmole})$ were purchased from PerkinElmer Life and Analytical Sciences (Boston, MA). The human dopamine, norepinephrine, and serotonin transporter cDNAs used in the experiments were described previously $[10,31,32]$. The cloning of mouse DAT cDNA was reported in an earlier publication [33]. The mouse NET and SERT CDNAs were amplified with nested PCR using mouse brain $\mathrm{cDNAs}$ as the template. The forward primers for mNET are: mNETf1 (CAGCCGCACCCATGCTTCT) and mNETf2 (AAAAGGTACCACCATGCTTCTGGCGCGAAT); the reverse primers are mNETr1 (TCCTCCACATTGCCAGGTTCAGA) and mNETr2 (AAAATCTAGAGGTTCAGATGGCCAGCCAGTG). The forward primers for mSERT are mSTf1 (AGCTAGTCAGGGTCCTTGGCAGATG) and mSTf2 (ATATCCATGGAGACCACACCTTTGAATTCTC), and reverse primers are $\mathrm{mSTr} 1$ (TGGGGCTTTTCAGAGATGAGGAGTC) and mSTr2 (TAATCTCGAGCCATGTCCTCTCCCTCAGTGTGTTAC). Restriction enzyme sites were incorporated in the primers for insertion into plasmid vectors. Oligonucleotide primers were synthesized by commercial DNA synthesis services. The correct sequences of $\mathrm{mNET}$ and mSERT were confirmed by sequence determination.

\section{Transient expression of the transporter cDNAs}

The transporter cDNAs were subcloned into the bluescript vector SKII+ (Strategene, La Holla, CA) which has a T7 promoter. The cDNAs were transiently expressed in monkey Intestine 407 cells (CCL-6, American Type Culture Collection, Rockville, MD) and characterized as described $[21,33]$. Briefly, cells were plated in 96-well plates, transfected with plasmid DNA using Lipofectin (Invitrogen Life Technologies, Carlsbad, CA) according to manufacturer's instruction, and infected with a recombinant vaccinia virus VTF-7 which carries the T7 polymerase gene [34].

\section{Transport measurement and drug inhibition}

After 20- to 24-hour incubation, the transfected cells were washed once with PBS/Ca/Mg (phosphate buffered saline solution supplemented with $1 \mathrm{mM} \mathrm{MgCl}_{2}, 0.1 \mathrm{mM}$ $\mathrm{CaCl}_{2}$ ), and then incubated for 10 minutes at $20^{\circ} \mathrm{C}$ in the same buffer containing $50 \mathrm{nM}\left[{ }^{3} \mathrm{H}\right]$-labelled substrate, 50 $\mu \mathrm{M}$ L-ascorbic acid (to protect the substrates from being oxidized), and different concentrations of the tested drugs (as described in Results or in each figure legend). At the end of the incubation, cells were washed 2 times with $\mathrm{PBS} / \mathrm{Ca} / \mathrm{Mg}$, and then dissolved in $0.1 \mathrm{M} \mathrm{NaOH}$. The amount of accumulated [ $\left.{ }^{3} \mathrm{H}\right]$-labelled substrate in the cells were determined by counting in scintillation fluid (MicroScint-20, PerkinElmer Life Sciences, Boston, MA) using a Packard TopCount, a microplate scintillation and luminescence counter. All experiments were performed in triplicates.

\section{Data analysis}

The $\mathrm{IC}_{50}$ values were determined by nonlinear regression of experimental data for each experiment according to a hyperbolic model using the computer program Origin (MicroCal Software, Northampton, MA). The $\mathrm{K}_{\mathrm{I}}$ values were then calculated from the $\mathrm{IC}_{50}$ values using the equation $\mathrm{K}_{\mathrm{I}}=\mathrm{IC}_{50} /\left(1+[\mathrm{S}] / \mathrm{K}_{\mathrm{M}}\right)$. Data are presented as arithmetic mean \pm SEM of four to seven independent experiments. ANOVA was used to determine statistical significance.

\section{Authors' contributions}

DDH carried out most of the experiments and data analyses, and drafted the manuscript. HHG conceived of the study, and participated in its design and coordination and helped to draft the manuscript. All authors read and approved the final manuscript.

\section{Acknowledgements}

This work was supported by a grant from National Institute on Drug Abuse (DA0I46/0). Some of the psychostimulants were kindly provided by National Institute on Drug Abuse through its Drug Supply Program. The authors also thank Dr. Michael Tilley for critical reading of the manuscript.

\section{References}

I. Harwood HJ, Fountain D, Fountain G: Economic cost of alcohol and drug abuse in the United States, 1992: a report. Addiction 1999, 94:631-635.

2. National Institute on Drug Abuse webpages: Commonly Abused Drugs [http://www.nida.nih.gov/DrugPages/DrugsofA buse.html]

3. NIDA: Overview of Findings from the 2003 National Survey on Drug Use and Health. Rockville, MD, Department of Health and Human Services, Substance Abuse and Mental Health Services Administration, Office of Applied Studies.; 2003.

4. Iversen LL: Role of transmitter uptake mechanisms in synaptic neurotransmission. Br J Pharmacol I97I, 41:57I-59I.

5. Kanner $\mathrm{BI}$, Schuldiner S: Mechanism of transport and storage of neurotransmitters. CRC Critical Reviews in Biochemistry 1987, 22:1-38.

6. Amara SG, Arriza JL: Neurotransmitter transporters: three distinct gene families. Current Opinion in Neurobiology 1993, 3:337-344.

7. Rudnick G, Clark J: From synapse to vesicle: the reuptake and storage of biogenic amine neurotransmitters. Biochimica et Biophysica Acta 1993, I I 44:249-263.

8. Ritz MC, Lamb RJ, Goldberg SR, Kuhar MJ: Cocaine receptors on dopamine transporters are related to self-administration of cocaine. Science 1987, 237:1219-1223.

9. Giros B, Caron MG: Molecular characterization of the dopamine transporter. Trends in Pharmacological Sciences 1993, I4:43-49.

10. Gu H, Wall SC, Rudnick G: Stable expression of biogenic amine transporters reveals differences in inhibitor sensitivity, kinetics, and ion dependence. Journal of Biological Chemistry 1994, 269:7I24-7I30.

11. Amara SG, Sonders MS: Neurotransmitter transporters as molecular targets for addictive drugs. Drug Alcohol Depend 1998, $51: 87-96$. 
12. Nestler EJ, Hyman SE, Malenka RC: Molecular neuropharmacology : a foundation for clinical neuroscience. New York, McGraw-Hill, Medical Pub. Div.; 2001 :xvi, 539 p..

13. Fleckenstein AE, Haughey HM, Metzger RR, Kokoshka JM, Riddle EL, Hanson JE, Gibb JW, Hanson GR: Differential effects of psychostimulants and related agents on dopaminergic and serotonergic transporter function. Eur J Pharmacol 1999, 382:45-49.

14. Eshleman A], Carmolli M, Cumbay M, Martens CR, Neve KA, Janowsky $A$ : Characteristics of drug interactions with recombinant biogenic amine transporters expressed in the same cell type. J Pharmacol Exp Ther 1999, 289:877-885.

15. Rothman RB, Baumann MH: Monoamine transporters and psychostimulant drugs. Eur J Pharmacol 2003, 479:23-40.

16. Rothman RB, Baumann MH, Dersch CM, Romero DV, Rice KC, Carroll FI, Partilla JS: Amphetamine-type central nervous system stimulants release norepinephrine more potently than they release dopamine and serotonin. Synapse 200I, 39:32-4I.

17. Kilty JE, Lorang D, Amara SG: Cloning and expression of a cocaine-sensitive rat dopamine transporter. Science I991, 254:578-579.

18. Koe BK: Molecular geometry of inhibitors of the uptake of catecholamines and serotonin in synaptosomal preparations of rat brain. I Pharmacol Exp Ther 1976, 199:649-661.

19. Richelson E, Pfenning M: Blockade by antidepressants and related compounds of biogenic amine uptake into rat brain synaptosomes: most antidepressants selectively block norepinephrine uptake. Eur J Pharmacol 1984, 104:277-286.

20. Wu X, Gu HH: Cocaine affinity decreased by mutations of aromatic residue phenylalanine 105 in the transmembrane domain 2 of dopamine transporter. Molecular Pharmacology 2003, 63:653-658.

21. Chen R, Han DD, Gu HH: A triple mutation in the second transmembrane domain of mouse dopamine transporter markedly decreases sensitivity to cocaine and methylphenidate. Neurochem 2005, 94:352-359.

22. Chen R, Wu X, Wei H, Han DD, Gu HH: Molecular cloning and functional characterization of the dopamine transporter from Eloria noyesi, a caterpillar pest of cocaine-rich coca plants. Gene 2005.

23. Giros B, Wang YM, Suter S, McLeskey SB, Pifl C, Caron MG: Delineation of discrete domains for substrate, cocaine, and tricyclic antidepressant interactions using chimeric dopaminenorepinephrine transporters. Journal of Biological Chemistry 1994 269: $15985-15988$

24. Henry LK, Field JR, Adkins EM, Parnas ML, Vaughan RA, Zou MF, Newman AH, Blakely RD: Tyr-95 and ile- 172 in transmembrane segments $I$ and 3 of human serotonin transporters interact to establish high affinity recognition of antidepressants. J Biol Chem 2006, 281:2012-2023.

25. Barker EL, Blakely RD: Identification of a single amino acid, phenylalanine 586, that is responsible for high affinity interactions of tricyclic antidepressants with the human serotonin transporter. Mol Pharmacol 1996, 50:957-965.

26. Barker EL, Perlman MA, Adkins EM, Houlihan WJ, Pristupa ZB, Niznik $H B$, Blakely RD: High affinity recognition of serotonin transporter antagonists defined by species-scanning mutagenesis. An aromatic residue in transmembrane domain I dictates species-selective recognition of citalopram and mazindol. Biol Chem 1998, 273: 19459-19468.

27. Giros B, el Mestikawy S, Godinot N, Zheng K, Han H, Yang-Feng T, Caron MG: Cloning, pharmacological characterization, and chromosome assignment of the human dopamine transporter. Molecular Pharmacology 1992, 42:383-390.

28. Volkow ND, Wang G], Fowler JS, Fischman M, Foltin R, Abumrad NN, Gatley SJ, Logan J, Wong C, Gifford A, Ding YS, Hitzemann R, Pappas N: Methylphenidate and cocaine have a similar in vivo potency to block dopamine transporters in the human brain. Life Sci 1999, 65:PL7-I2.

29. Parran TVJ, Jasinski DR: Intravenous methylphenidate abuse. Prototype for prescription drug abuse. Arch Intern Med I99I, 1 5 1:781-783.

30. Schuldiner S, Steiner-Mordoch S, Yelin R, Wall SC, Rudnick G: Amphetamine derivatives interact with both plasma membrane and secretory vesicle biogenic amine transporters. Molecular Pharmacology 1993, 44:1227-|231.
31. Smicun Y, Campbell SD, Chen MA, Gu H, Rudnick G: The role of external loop regions in serotonin transport. Loop scanning mutagenesis of the serotonin transporter external domain. J Biol Chem 1999, 274:36058-36064.

32. Gu HH, Wu X, Giros B, Caron MG, Caplan MJ, Rudnick G: The NH(2)-terminus of norepinephrine transporter contains a basolateral localization signal for epithelial cells. Molecular Biology of the Cell 200I, I 2:3797-3807.

33. $\mathrm{Wu} X \mathrm{H}, \mathrm{Gu} \mathrm{HH}$ : Molecular cloning of the mouse dopamine transporter and pharmacological comparison with the human homologue. Gene 1999, 233:163-170

34. Blakely RD, Clark JA, Rudnick G, Amara SG: Vaccinia-T7 RNA polymerase expression system: evaluation for the expression cloning of plasma membrane transporters. Analytical Biochemistry 1991, 194:302-308.
Publish with Biomed Central and every scientist can read your work free of charge

"BioMed Central will be the most significant development for disseminating the results of biomedical research in our lifetime. "

Sir Paul Nurse, Cancer Research UK

Your research papers will be:

- available free of charge to the entire biomedical community

- peer reviewed and published immediately upon acceptance

- cited in PubMed and archived on PubMed Central

- yours - you keep the copyright 